\title{
esboços
}

histórias em contextos globais

\section{OS PLÁUCIOS, A EMANCIPAÇÃO DA PLEBE E A EXPANSÃO ROMANA: \\ CONECTANDO AS HISTÓRIAS INTERNA E EXTERNA DA REPÚBLICA ROMANA}

The Plautii, the Emancipation of Plebs and the Roman Expansion:

Connecting the Internal and External Histories of the Roman Republic

José Ernesto Moura Knust ${ }^{\mathrm{a}}$ (D) https://orcid.org/0000-0002-3295-9107

E-mail: zeknust@gmail.com

a Instituto Federal Fluminense, Macaé, RJ, Brasil

DOSSIÊ

Toda história é história conectada? 


\title{
RESUMO
}

A história da República Romana normalmente é dividida entre fenômenos internos, como lutas sociais e transformações institucionais, e externos, como guerras e conquistas. A crítica ao internalismo metodológico desenvolvido pela história global tem trazido uma importante discussão sobre as definições de internalidade e externalidade e sobre as conexões históricas entre processos que antes eram tomados como internos ou externos. Ao longo do século IV a.C. acontecem importantes transformações tanto no que tradicionalmente se toma como "história interna" romana (a emancipação da plebe) quanto no que seria sua "história externa" (a reorganização e a consolidação da dominação romana sobre a Itália central). $\mathrm{O}$ intuito deste artigo, tendo por ponto de partida o estudo de caso da atuação política da família dos Pláucios, é mostrar que podemos entender as transformações da época como partes de um mesmo processo histórico: a rearticulação dos grupos sociais da Itália central. Assim, emancipação da plebe e expansão romana não são meros processos históricos coevos e paralelos, mas facetas de um mesmo processo histórico, maior e de escopo geográfico mais amplo.

\section{PALAVRAS-CHAVE}

República Romana. Expansão romana. Internalismo metodológico.

\begin{abstract}
The history of the Roman Republic is often divided between internal events such as social struggles and institutional transformations and external events such as wars and conquests. The critique of methodical internalism developed by Global History has sparked an important discussion on the definitions of internality and externality and on the historical connections between processes that were formerly taken as internal or external. Throughout the fourth century BCE, important changes took place both in what is traditionally taken as Roman "internal history" (the emancipation of the plebs) and in what is taken as "external history" (the reorganization and consolidation of Roman domination over central Italy). The objective of this article, whose starting point is the political action of the Plautii family, is to argue that we can understand the transformations of that time as pieces of the same historical process: the rearticulation of social groups in central Italy. Therefore, the emancipation of the plebs and the Roman expansion are not mere contemporaneous and parallel historical processes, but facets of the same historical process, which is larger and has an ampler geographical scope.
\end{abstract}

\section{KEYWORDS}

Roman Republic. Roman expansion. Methodological internalism. 
$\mathbf{U}$ $m$ dos grandes nomes da história social da Roma Antiga no século XX, o inglês Peter A. Brunt escreveu certa vez que a história das lutas sociais dentro de Roma ao longo do período republicano se acelerava quando a história dos conflitos externos romanos se refreava, e vice-versa (BRUNT, 1986). Essa afirmação revela uma ideia fundamental dos estudos sobre os fatos da República Romana: a existência de uma separação essencial entre histórias "interna" e "externa" de Roma. Se olharmos os sumários das grandes obras de síntese sobre o período, não é difícil identificar os capítulos ou seções que tratam de um e do outro.

A despeito de certa "italianização" dos estudos sobre o período republicano, estimulados sobretudo pela arqueologia, mas também pela epigrafia (BRADLEY; ISAYEV; RIVA, 2007; FARNEY; BRADLEY, 2017; ROTH, 2007; ROTH; KELLER, 2007; TORELLI, 1999), as grandes narrativas que orientam a organização da pesquisa histórica e do ensino de história sobre a República Romana ainda são determinadas por essa divisão entre histórias interna e externa. Os grandes temas historiográficos sobre esse período se enquadram naquela - como as instituições políticas romanas se formaram? o que dava a dinâmica dos conflitos sociais dentro de Roma? - ou nesta - quais foram os motivos da expansão romana? como conseguiram fazê-la de maneira tão bem-sucedida? como os povos italianos foram romanizados?

Quando muito, algumas grandes questões são colocadas sobre a interação entre as duas - quais foram as consequências da expansão externa para os diferentes grupos sociais dentro de Roma? como os conflitos internos de Roma moldaram sua política expansionista? -, mas ainda assim são tomadas como dois objetos distintos.

A expansão romana é entendida como a expansão de uma institucionalidade (a res publica romana) que cresce territorialmente e incorpora aquilo que antes lhe era externo. Trata-se de uma expansão centrífuga; isto é, ao longo do tempo, o que é "interno" cresce para fora, transbordando e tomando o que estava fora de si. Tal expansão em nenhum momento é essencialmente conectada às transformações da própria institucionalidade. Estas são vistas como resultado de processos endógenos ou desdobramentos endógenos da expansão. A coisa se expande e se transforma, e essas expansão e transformação podem até se influenciar mutuamente, mas são processos distintos, duas histórias que correm lado a lado, às vezes se influenciando.

Uma das questões aqui é uma naturalização da noção de soberania territorial - acabamos pensando a expansão romana como a de uma forma de poder territorial que é típica do Estado-nação moderno. Assim, territórios vão aos poucos sendo incorporados à abstração Roma, expandindo a história interna por meio da incorporação do que antes era história externa. Mapas históricos que mostram as fases da expansão romana são a síntese visual perfeita dessa forma de pensar.

Uma das mais importantes contribuições epistemológicas da ascensão da história global tem sido questionar a primazia explicativa dada às questões internas, aquilo que se convencionou chamar, de forma crítica, de internalismo metodológico. Um dos pontos nodais dessa crítica é justamente o questionamento da distinção entre internalidade e externalidade histórica (CHERNILO, 2011, 2017; MATIN, 2013).

Um ponto fundamental desse questionamento diz respeito à forma como determinadas abstrações são tomadas como entidades discretas entre si. Encaradas como autossuficientes, é dado a elas o estatuto epistemológico de contêiner que encerra a história interna (CONRAD, 2016, p. 3) e de unidade básica de interação com outros seres similares na história externa. É nessa lógica que a história interna de Roma é a da "sociedade romana" - uma história de conflitos entre patrícios e 
plebeus e de mudanças das instituições republicanas - e a externa é a da interação de Roma com sociedades vizinhas - uma narrativa de conquista e expansão. Roma e sociedade romana são essas abstrações tomadas como criaturas discretas pela historiografia dedicada à República Romana.

Um dos caminhos para superar esse problema é entender quais eram as diversas organizações políticas da Itália central no período e suas formas de interação. Mas, para isso, precisamos estar preparados para entender a dinâmica das transformações dessas sociedades, posto que não permanecem estáticas conforme interagem entre si. Mais uma vez, é preciso frisar: isso não significa meramente entender as relações entre as transformações internas dessas organizações e sua história de interações externas. É preciso conectar o que tradicionalmente se separa como histórias interna e externa em uma única narrativa, porque estamos diante de um único processo que se desenrola em dinâmicas de escalas geográficas diversas.

Assim, a formação e a transformação dessas comunidades e instituições devem ser entendidas por dinâmicas que vão além de si mesmas. A própria expansão dessas comunidades e instituições pode ser resultado das mudanças nessas dinâmicas, que não são determinadas de dentro da comunidade. Isto é, podem existir expansões centrípetas quando aquilo que era externo se imiscui para dentro, transformando nesse processo o contexto interno. A coisa que se expande se transforma, ou, melhor dizendo, se expande porque se transforma de dentro para fora.

Inspirado nessa contribuição epistemológica da história global, pretendo contribuir neste artigo para o projeto acima delineado, analisando um momento que até historiadores da Antiguidade, acima de todos Tito Lívio, reconhecem como crucial tanto para o que é tratado como história interna de Roma - a grande vitória dos plebeus em seu conflito com os patrícios, ao obterem o direito à eleição para as mais altas magistraturas romanas - quanto para o que é entendido como história externa a vitória romana sobre a rebelião das cidades latinas e a reorganização do sistema de alianças romano, que impõe sua hegemonia sobre a Itália central.

Darei especial atenção, à guisa de estudo de caso, à atuação política de uma família plebeia romano-itálica, os Pláucios, neste contexto histórico. Pretendo mostrar aqui que a história dos Pláucios nos ajuda a entender que a "emancipação da plebe" e a "expansão romana" são fenômenos históricos muito mais conectados do que normalmente se supõe.

\section{A EMANCIPAÇÃO DA PLEBE, MAS O QUE ERA A PLEBE?}

Comecemos pelo que foi tomado como a história interna da República Romana. Os cidadãos romanos, reunidos na Assembleia das Centúrias, elegeram Caio Fábio Ambusto e Caio Pláucio Próculo para o consulado no ano de 358 a.C. (Tito Lívio, Desde a fundação da Cidade, 7.12; BROUGHTON, 1951, p. 121). Essa era a nona eleição anual desde a Lei Licínia-Séxtia de 367 a.C., que, entre outras coisas, punha fim à possibilidade de suspensão do consulado para a eleição de tribunos militares com poder consular, consolidando, assim, o modelo de dois cônsules como a mais alta magistratura da República Romana. A um primeiro olhar, essa eleição não parece muito interessante, e raramente chamou a atenção dos historiadores.

A eleição de Caio Fábio para cargo tão prestigioso e importante não poderia nos causar surpresa alguma. A gens Fábia era uma das mais tradicionais famílias patrícias 
da República Romana. Caio Fábio era apenas mais um Fábio a atingir tamanha glória. Seu xará e parceiro de consulado não tinha genealogia similar, é verdade. Muito pelo contrário, Caio Pláucio Próculo foi o que os romanos chamavam de "homem novo", o primeiro de sua família a ocupar a mais alta magistratura. Os Pláucios sequer são mencionados pelas narrativas históricas antes dessa eleição em 358 a.C. Caio Pláucio era um homem novíssimo.

Sua eleição, contudo, nunca foi tratada como um enigma pela historiografia. A Lei Licínia-Séxtia de 367 a.C., para além de estabilizar o consulado como magistratura mais importante, fez sua fama por abrir a possibilidade de membros de famílias não patrícias serem eleitos cônsules. Caio Pláucio foi, nesse contexto, o sexto plebeu eleito cônsul depois de 367 a.C. A pergunta que sempre prendeu a atenção dos historiadores foi por que a Lei Licínia-Séxtia fora aprovada.

Os historiadores modernos encontraram em Tito Lívioalgo além de nossa principal fonte de informações sobre o período. Encontram também um modelo interpretativo. Ainda que Dioniso de Halicarnasso, a outra grande fonte de informações para o início da história romana, seja relevante para o estudo de alguns temas específicos do período, é sem sombra de dúvida a obra de Tito Lívio que estabeleceu as bases fundamentais para sua interpretação geral. Vem de Lívio o próprio enquadramento geográfico de uma história interna, na qual the preocupa sobretudo o conflito entre as ordens - isto é, as disputas entre patrícios e plebeus -, e uma externa, em que a questão da guerra e da paz surge como fundamental.

Seguindo esse enquadramento geográfico - que se alinhava à historiografia nascida no berço do Estado-nação -, a historiografia moderna acomodou a questão da Lei Licínia-Séxtia na gaveta da história interna, dentro da qual a questão dos conflitos entre patrícios e plebeus era a causa motriz fundamental.

Com essa lógica, produziu-se um modelo interpretativo que explicava tal lei. Os cidadãos romanos alijados dos espaços de poder pela fechada elite política patrícia, por meio de um longo processo de conflitos e reivindicações, que tiveram nas famosas sedições da plebe seus momentos decisivos, teriam obtido vitórias que, ao longo do tempo, foram abrindo o sistema político romano aos plebeus. A esse processo se dá o nome de "emancipação da plebe". A lei de 367 a.C., que, entre outras coisas, dava aos plebeus o direito à eleição para o consulado - e que nos permitia explicar por que Caio Pláucio Próculo fora eleito em 358 a.C. -, era parte desse processo.

"Como os plebeus conseguiram tamanha vitória?" é a pergunta que se impõe em seguida. A explicação hegemônica sobre a emancipação da plebe aponta como fato primordial a formação de uma nobreza patrício-plebeia, isto é, uma nova elite política e econômica que incluía famílias não patrícias. Em parte, as conquistas plebeias, como a abertura do consulado para os plebeus, seriam, então, resultado da ascensão social e econômica de uma fração dos plebeus. Por outro lado, essa mesma abertura teria reforçado o processo histórico, incluindo essa fração no seio da elite política romana e consolidando sua ascensão social.

O modelo de narrativa histórica usado nessa explicação me parece emular, ao menos em parte, a imagem tradicional da relação entre burgueses e aristocratas na Europa dos séculos XVIII e XIX. De uma posição inicial de conflito, emergem alianças a partir do momento em que setores da burguesia conseguem grande ascensão social por conta de seu enriquecimento, atraindo o interesse por alianças - inclusive matrimoniais - das famílias tradicionais. Substituindo burgueses por plebeus e nobres 
por patrícios, temos a explicação tradicional para a formação da nobilitas patrício-plebeia (CASSOLA, 1988; CORNELL, 1995, p. 340-344).

Ao longo do tempo, a historiografia se esmerou em precisar, refinar e subverter nossa compreensão sobre quais eram as partes desse conflito. Posto de maneira mais simples, há décadas se discute quem eram realmente os patrícios e o que foi de fato o movimento plebeu. Nas duas questões, o entendimento tradicional ancorado em Tito Lívio foi desafiado por propostas historiográficas bastante sólidas. No caso da identificação dos patrícios, o trabalho de Gaetano de Sanctis teve bastante êxito em mostrar que todas as nossas fontes, até Tito Lívio, nos permitem entrever dados que mostram que o patriciado se tornou uma elite política fechada e exclusivista em um momento bastante avançado do que seria a história do conflito (DE SANCTIS, 1907; CORNELL, 1995, p. 254-255).

A retórica patrícia vende a origem de seus privilégios como provenientes de um estado de coisas primordial, o que acabou enganando a historiografia desde Tito Lívio. Contudo, estaríamos diante de tradições inventadas, para usar o termo consolidado por Eric Hobsbawm e Terence Ranger (HOBSBAWM; RANGER, 1997), para legitimar um processo de "fechamento do patriciado" entre o fim do século $\mathrm{V}$ e o início do século IV a.C.

Diante dessa reinterpretação do que foi o patriciado, também foi necessário reinterpretar a plebe, posto que esta em geral foi entendida como o conjunto de todos aqueles excluídos do patriciado. Acredita-se hoje que o movimento plebeu tenha sido um movimento político-social mais específico, que envolveu determinados grupos sociais enfrentando a crescente pretensão do patriciado de monopolizar o controle sobre elementos fundamentais da comunidade política romana, mas não envolveu todos aqueles que não eram patrícios.

Nas palavras de Tim Cornell, "o movimento plebeu que criou a plebe, e não o contrário" (CORNELL, 1995, p. 257), isto é, organização da luta política em oposição ao patriciado, criou um movimento político que, por sua vez, delineou uma identidade plebeia. O grande debate passa a ser, porém, justamente sobre quem eram essas pessoas que tomaram parte do movimento plebeu. A falange hoplítica (RAAFLAUB, 1993) e os infra classem, isto é, os excluídos do Exército (MOMIGLIANO, 2005, p. 178180; CORNELL, 1995, p. 257), são dois grupos citados quando se busca identificar o grupo social que dá forma inicial à plebe, ainda que a formação da nobreza patrício-plebeia entre os séculos IV e III a.C. deixe claro que o movimento plebeu passara, em algum momento, a incluir grupos sociais em melhores condições econômicas, incorporando setores da classe dominante em seu enfrentamento ao patriciado.

O mais importante nisso, como bem aponta Christopher Smith, é perceber que um movimento político que durou mais de duzentos anos dificilmente manteria características sociais e políticas idênticas ao longo de todo o período (SMITH, 2006, p. 257; RAAFLAUB, 2005a). Essa percepção da historicidade do elemento plebeu tem sido o ponto central das análises sobre a plebe e sua atuação política e não nega, em essência, a ideia central tradicional de que a vitória plebeia esteve diretamente relacionada à existência de plebeus ricos e importantes em Roma.

Pensando nos termos do debate epistemológico posto pela ascensão da história global, contudo, nenhuma dessas discussões realmente rompe com a lógica do "internalismo metodológico". O contexto que explica as transformações históricas observáveis continua sendo uma dinâmica que se desenrola nas entranhas do que definimos abstratamente como sociedade romana. É bem verdade que essa história 
pode ser - e inúmeras vezes o foi - conectada a um contexto mais amplo de conflitos sociais que seriam típicos das cidades-Estado grecorromanas em formação.

As lutas sociais, o que os gregos chamavam de stasis, que invariavelmente envolviam os temas do acesso à terra, da escravidão por dívidas e do acesso à cidadania ativa (FUKS, 1984; STE. CROIX, 1989, cap. IV e V), parecem uma constante na história mediterrânica antiga, da qual o conflito entre patrícios e plebeus poderia ser visto como apenas um caso (RAAFLAUB, 2005b). No entanto, estamos diante de uma comparação entre histórias cuja dinâmica sempre é dada por fatores internos os conflitos sociais locais da comunidade. Afora essa comparação entre elementos formais de histórias que correriam paralelas, pouco se explorou essa similaridade na direção de identificar verdadeiras conexões e explicações para além das "fronteiras" de cada uma das ditas "sociedades".

Essa abordagem internalista certamente tem valor explicativo. Suas bases empíricas são sólidas, inclusive. Com base em uma prosopografia dos magistrados do período, é possível identificar que certos grupos e famílias patrícios estão criando laços de aliança política com grupos e famílias plebeus, dada a concomitância frequente de comagistraturas entre membros de famílias patrícias e plebeias específicas (FORSYTHE, 2006, p. 269-270).

Ademais, das seis famílias plebeias que elegem cônsules nos vinte primeiros anos após a lei de 367 a.C., sabemos que cinco delas já haviam elegido magistrados importantes no primeiro século e meio de República, entre tribunos da plebe e militares com poder consular. Isto é, eram famílias plebeias já com alguma relevância política na sociedade romana antes da abertura do consulado para os plebeus. Encaixam-se bem, portanto, na narrativa de famílias plebeias que ascendem, mais cedo ou mais tarde, a uma posição social e política de destaque, possivelmente associada também a uma posição econômica privilegiada, e que depois disso obtêm sucesso com a abertura do consulado aos plebeus.

Não há razões para desacreditar por completo a tese de que as transformações que a República romana sofre estão diretamente ligadas à ascensão social de um grupo de famílias plebeias dentro de Roma, que muda a balança do jogo social, econômico e político.

Os Pláucios, porém, constituem um enigma nesse quadro explicativo e são a exceção entre as seis famílias que elegem cônsules nos vinte primeiros anos depois de 367 a.C. Dentro do que podemos saber, nunca haviam ocupado qualquer magistratura antes de ter seu primeiro cônsul, e nada se sabe sobre sua ascensão em Roma. Poderíamos estar diante de um exemplo que se faz desimportante pela sua própria escassez de informações - sabemos pouco sobre os Pláucios porque os Pláucios são pouco importantes. Contudo, as informações que temos mostram os Pláucios como uma importante família na política romana da segunda metade do século IV a.C. Além de Caio Pláucio Próculo, vários outros membros da família elegem-se cônsul nas décadas seguintes.

Em 347, 341, 330, 329 e 328 a.C. temos cônsules Pláucios, e em 312 a.C. temos um censor da família (BROUGHTON, 1951, p. 130, 134, 143-145, 154). É significativo que, entre 330 e 328 a.C., os Pláucios tenham enfileirado três eleições para cônsul, façanha repetida por pouquíssimas famílias (TERRENATO, 2014, p. 50).

Estamos diante de uma família claramente relevante no cenário político romano que veio, ao que parece, do nada. Ou seria uma miopia romanocêntrica que estaria nos impedindo de ver de onde vieram os Pláucios? O arqueólogo italiano Nicola Terrenato 
teve sua atenção despertada por essa família e levantou o que era possível saber sobre os Pláucios. Logo percebeu que havia algo a ser perseguido ali, e, de enigma, os Pláucios se transformam na chave para mudar o enquadramento geográfico que usamos para entender a dinâmica política da República Romana.

Além da informação de seus primeiros membros eleitos cônsules, presente nos fasti e em Tito Lívio, as duas menções mais antigas aos Pláucios provêm de inscrições de difícil interpretação encontradas fora de Roma. Em uma inscrição datada do início do século IV a.C. encontrada na Tumba dos Relevos, na cidade etrusca de Cere, pode-se ler o nome plavti. Pelo contexto em que se encontrou a inscrição, ela foi entendida como referência a uma Pláucia, provavelmente casada com um homem do importante clã local Maturna, proprietária da tumba.

Em outra inscrição, em uma cista de bronze encontrada na cidade latina de Preneste e datada do fim do século IV a.C., pode-se ler Novios Plautios med Romai fecid (isto é, "Nóvio Pláucio me fez em Roma"). Nóvio é um nome de origem campana e não se conhece em toda a história antiga outro Pláucio que tenha tido esse nome, o que levou Theodor Mommsen a lançar mão da ideia de que Nóvio seria um escravo ou liberto campano ligado aos Pláucios.

Outra interpretação possível, porém, é a de que Nóvio seria um legítimo membro da família Pláucia, teria encomendado a produção dessa cista e possivelmente tinha alguma relação com a Campânia. Em qualquer um dos casos, a descoberta dessa cista em Preneste serve como bom indício da presença dos Pláucios na cidade, o que converge com o que se sabe sobre a família durante os séculos seguintes, dado que uma série de inscrições do período republicano encontradas tanto em Preneste quanto na vizinha Tibur trazem menção a ela (TERRENATO, 2014, p. 47-53).

Quem eram os Pláucios no século IV a.C.? A melhor resposta que podemos dar é que estamos diante de uma família com raízes nas cidades latinas de Preneste e Tibur, com relações políticas estabelecidas pela via matrimonial ao menos com a cidade etrusca de Cere, que nessa época parece ter tido relações próximas com Roma (RUOFF-VÄÄNÄNEN, p. 1975, p. 43-44; HARRIS, 1971, p. 45-47; CORNELL, 1995, p. 320-321), e que por fim aparece elegendo cônsules romanos ao longo de toda a segunda metade do século.

Os Pláucios não eram, percebe-se ao juntar essas peças do quebra-cabeça, uma mera família romana plebeia em ascensão social. Para entender quem eram eles e por que elegeram tantos cônsules ao longo do século IV a.C., entender Roma parece não ser o bastante. A circulação de membros das elites mediterrânicas por diferentes comunidades é um fenômeno há muito já identificado (AMPOLO, 1977), mas ainda pouco explorado em termos de construção de explicações históricas. A principal barreira a isso, sem dúvidas, é a hegemonia que o internalismo metodológico ainda mantém na estrutura explicativa dos historiadores.

A emancipação da plebe ganha, assim, um novo quadro geográfico de explicação, não mais limitado ao que se convencionou chamar "sociedade romana". Sem negar a importância de famílias baseadas em Roma que eram excluídas da fechada elite patrícia e cuja ascensão social e econômica forçava a rigidez do sistema, a existência de famílias poderosas baseadas em outras cidades da região central da Itália entrando no sistema político romano pela via do movimento plebeu também precisa ser levada em consideração para perceber tal processo histórico.

Algo para além de Roma precisa ser entendido para compreender a chegada dos Pláucios às altas magistraturas romanas. Ao concebermos os Pláucios, talvez 
sejamos capazes de interpretar Roma para além de si mesma e, assim, fugir do internalismo metodológico.

O que melhor conhecemos sobre os Pláucios do século IV a.C. é justamente o que os membros da família fizeram enquanto foram altos magistrados romanos. Em 358 a.C., os cônsules eleitos foram designados para fazer a guerra contra tarquinenses ao norte e privernates ao sul, enquanto um ditador foi designado para fazer frente à ameaça ainda maior: o ataque gaulês. Diante de tantas frentes de batalha, segundo Tito Lívio, um sorteio definiu que as primeiras legiões romanas a serem comandadas por um Pláucio seriam responsáveis pela guerra com Priverno, uma cidade ao sul de Roma razoavelmente próxima a Tibur e Preneste.

Terrenato, contudo, chama a atenção para o fato de esse ser um sorteio estranhamente propício aos dois cônsules. Enquanto Caio Pláucio Próculo ficou responsável pela guerra em uma região um pouco ao sul de uma área com a qual sua família tinha claras ligações, Caio Fábio Ambusto recebeu o comando de tropas em uma região onde os Fábios historicamente haviam lutado famosas batalhas: a fronteira com a Etrúria (Tito Lívio, Desde a fundação da Cidade, 7.15; TERRENATO, 2014, p. 49).

Em 341 a.C., Tito Lívio conta que nova guerra com Priverno é causada pelo ataque desta às colônias de Norba e Sécia. Mais uma vez há um Pláucio eleito cônsul, Caio Pláucio Venão, em seu segundo mandato. E, mais uma vez, o sorteio define o cônsul Pláucio como responsável pela guerra com Priverno (Tito Lívio, Desde a fundação da Cidade, 8.1). Terrenato tem razão em desconfiar desses sorteios, que, para Tito Lívio, definiam aleatoriamente os responsáveis pelas campanhas militares. Mas a questão vai muito além dos sorteios. A própria relação entre consulados de Pláucios e guerras com Priverno fica inconteste quando identificamos que o terceiro e maior conflito entre Roma e Priverno - quando esta, aliada a Fundos, ataca as colônias romanas de Sécia, Norba e Cora - ocorre justamente nos anos de apogeu do poder político da família no século IV a.C., quando ela emplaca três cônsules seguidos (Tito Lívio, Desde a fundação da Cidade, 8.19-20).

Como bem sentencia Terrenato, ou a eleição de um Pláucio em Roma era relevante o suficiente para enervar os ânimos em Priverno, ou os Pláucios sistematicamente lideram os exércitos romanos sob suas ordens para ataques na área, depois narrados como guerras defensivas. Em qualquer opção, fica claro o que Terrenato chamou de uma "agenda pláucia" em relação à região (TERRENATO, 2014, p. 50).

Ao estudar os Pláucios, Terrenato está especialmente interessado no fato de uma família utilizar os meios institucionais da República para agendas privadas. Seu ponto está em mostrar a importância do elemento clânico na organização da vida política italiana. Mas seu exemplo também mostra que as guerras de conquista romanas têm uma relação intrínseca com a dinâmica política interna. Afinal, foi a Lei Licínia-Séxtia que permitiu aos Pláucios terem a possibilidade de usar esses meios institucionais romanos para sua agenda. Cabe aqui perguntar qual foi a relação entre a abertura das altas magistraturas romanas à plebe e as transformações no contexto das guerras expansionistas romanas. Essa história externa passava por momentos decisivos justamente nesse período. 


\section{A EXPANSÃO DE ROMA, MAS O QUE ERA ROMA?}

Olhemos agora, então, com mais atenção para o que se entende por história externa de Roma. Em episódio bem mais renomado do que as aventuras militares dos Pláucios, Tito Lívio conta, com indubitável floreio literário, que um dos cônsules do ano 338 a.C., Lúcio Fúrio Camilo, proferiu um discurso persuasivo ao Senado sobre a situação das cidades latinas (Tito Lívio, Desde a fundação da cidade, 8.13). Três anos antes, um grande número dessas cidades havia se unido a campânios e sedicinos em um grande levante anti-Roma, originando uma enorme rebelião que alguns chamam de Guerra Latina - ou Segunda Guerra Latina, para diferenciá-la de outro conflito com os latinos ocorrido na primeira década da República. Derrotada a revolta, tratava-se agora de como lidar com os derrotados.

Lívio, por meio da recriação inventiva do discurso de Camilo ao Senado, nos conta que este teria convencido os senadores da necessidade de reconstruir a relação com os latinos derrotados em bases misericordiosas, para garantir com isso a grandeza de Roma. O Senado teria então, ainda segundo Lívio, analisado caso a caso a situação das cidades latinas e estabelecido punições e novas condições de aliança com Roma que, em essência, significavam diferentes tipos de relação de inserção no sistema político republicano (Tito Lívio, Desde a fundação da cidade, 8.14).

Há tempos, identificou-se que esse momento marca uma transformação importante na forma como Roma se relaciona com as regiões sob sua hegemonia. Roma teria proibido as cidades sob sua influência de estabelecerem alianças paralelas entre si. Isso determina o fim da possibilidade de criar ligas, forma bastante importante de interação entre as cidades-Estado da época, e impõe que todas as cidades passem a se relacionar diretamente com Roma em condições que variam dentro de uma hierarquia. Sob essa lógica, a res publica romana passa a ser incontestavelmente o centro de articulação do poder na Itália central.

Uma abordagem que já foi muito corrente apregoava que, nesse processo de redefinição das relações entre Roma e as cidades latinas, havia sido criado o modelo de formas específicas de enquadramento institucional dos aliados que duraria até a Guerra Social (CORNELL, 1995, p. 348-353; HUMBERT, 1978).

Algumas cidades se tornam municípios com cidadania plena; isto é, mantêm instituições próprias, mas são cidadãos romanos, seguindo o modelo do que teria sido o primeiro município romano: Túsculo. Outras se tornam municípios sem direito a voto, caso similar ao anterior, mas com a diferença importante de que sua cidadania romana não lhes garantia direito a participar das assembleias romanas. Outras cidades recebem o status de aliadas: mantêm-se independentes, mas submetidas a tratados de aliança com Roma que as obriga a enviar tropas quando requisitadas. E outras mais recebem o status de colônias latinas, passando a ser regidas por uma noção inspirada no Direito que era compartilhado entre as cidades latinas; isto é, são cidadãos de suas próprias cidades, mas quando em Roma têm alguns direitos específicos e podem inclusive tornar-se cidadãos romanos depois de um tempo de residência na cidade.

Acredita-se hoje, contudo, que o mais provável é que essa tipologia seja o resultado de um processo mais gradual de construção de relações entre Roma e suas "aliadas" durante o fim do século IV e o século II a.C., quando uma miríade de diferentes 
tipos de relações específicas foi sendo progressivamente enquadrada nesses quatro modelos mais gerais (MOURITSEN, 2007; SCOPACASA, 2015, p. 149-150).

Seja como for, ainda predomina uma ideia de interação entre entidades políticas tomadas como dadas. Roma, como agente dessas interações, é tanto uma abstração quanto Priverno ou Veios. É claro que as identidades étnicas e as estruturas institucionais que essas abstrações envolvem eram fatores concretos para a realidade histórica de seu tempo. Contudo, os historiadores modernos tendem recorrentemente a reificar essas abstrações como sujeitos em si. Filhos de uma historiografia que teve no Estado-nação seu eixo constituinte, facilmente cedemos à fantasmagórica figura do Estado-nação o papel de sujeito histórico, até quando não existem Estados-nação.

Marc Bloch disse que o historiador é como o ogro da lenda, que, ao farejar o humano, sabe que ali está sua caça (BLOCH, 2002, p. 54). Quando cedemos a essas abstrações um tanto vazias de conteúdo social, acabamos perdendo a trilha da caça. Evitar ao máximo usar Roma como sujeito de uma frase, forçando-nos a refletir sobre que sujeitos históricos realmente estavam realizando a ação que atribuímos a essa abstração fantasmagórica, pode ser um bom exercício olfativo.

Quem estava, então, fazendo acordos e alianças, montando o sistema hegemônico que transformou as instituições políticas da res publica romana no centro de poder incontestável da Itália central na segunda metade do século IV a.C.? Tito Lívio atribui esse papel ao Senado, mas é provável que isso seja um anacronismo. $\mathrm{Na}$ época de Tito Lívio, tais acordos eram atribuição do Senado, por isso ele dá ao Senado do século IV a.C. esse papel. Contudo, é só um pouco depois do fim da Guerra Latina, e isso mais uma vez não é uma coincidência, que o Senado começou a ganhar a forma tradicional pela qual ficou conhecido na história romana.

ALei Ovínia, sobre cuja data existe muita incerteza, mas aprovada provavelmente entre 339 e 318 a.C. (CORNELL, 1995, p. 369), instituiu que os censores definiriam os membros do Senado (Festo, Sobre o significado das palavras, 290L). Com isso, a condição de ser um senador passa a ser algo mais estável, quase sempre vitalício, dado que, por mais que um censor pudesse excluir alguém do Senado, essa parece ter sido uma medida drástica tomada apenas em ocasiões muito específicas.

Isso acontece paralelamente a mudanças nas magistraturas curuis. Uma das três Leis Genúcias de 342 a.C. proibia o acúmulo de magistraturas e o exercício de uma mesma magistratura pela mesma pessoa dentro de um prazo de dez anos. Isso punha fim à prática recorrente de alguns nomes importantes da política romana se revezarem no poder, facilitando o acesso à magistratura para outras pessoas dentro desse grupo dominante. Fica claro aqui que grupos da classe dominante romana estão ativamente buscando a construção de uma oligarquia mais ampla, de um sistema que seja controlado de maneira mais horizontal por um grupo maior da classe dominante, do que acontecia no auge do "fechamento do patriciado".

A ascensão do Senado como corpo central do sistema, um local em que o conjunto da elite política dessa classe dominante era capaz de controlar coletivamente as ações individuais dos magistrados, é a culminância desse processo (CORNELL, 1995, p. 371-373).

Essa oligarquização da política romana foi tradicionalmente tratada como resultado da história interna. Mas, se a conectarmos com a reorganização da relação com as cidades aliadas e com a presença itálica na plebe que se emancipa, uma realidade mais complexa começa a emergir. 
Entre a década de 360 e o fim do século IV a.C., as instituições da res publica se transformam significativamente e passam a articular grupos diferentes daqueles que haviam articulado no auge do fechamento do patriciado. Esse processo não foi plenamente compreendido por causa de seu fatiamento em histórias interna e externa. Tirar a agência histórica das abstrações estatais e identificá-la nos grupos sociais, ao mesmo tempo que se olha para além dos recortes geográficos estabelecidos por essas abstrações, é o caminho necessário. Em vez de agentes históricos, tais abstrações estatais precisam ser entendidas como plataformas para a agência de diferentes grupos sociais.

Mencionei antes que Terrenato tem no papel dos clãs uma de suas teses centrais sobre a política na Itália antiga. Ele parte do pressuposto de que a política italiana durante séculos já era controlada por grandes linhagens de parentesco (real ou fictício/mítico), o que ele chama de clãs e associa às gentes mencionadas nas fontes literárias. Em um texto em que trata da formação da cidade-Estado arcaica romana, ele identifica justamente a agência histórica desses clãs.

Segundo o modelo que propõe, os clãs buscam e constroem locais para sua convergência e negociação estratégica. Santuários e festivais religiosos desempenham um papel importante nisso, mas logo a cidade desponta como o espaço primordial dessa interação clânica (TERRENATO, 2011, p. 240-242). As instituições da cidadeEstado surgiriam, assim, da sedimentação histórica de acordos e associações criados por determinados clãs de uma ampla região sobre um espaço político específico.

É discutível quanto temos realmente elementos para identificar na arqueologia da Itália pré-romana a presença ubíqua desses clãs que, segundo Terrenato, marcariam a história italiana na longa duração (TERRENATO, 2011, p. 237-240; versus SMITH, 2006, p. 144-163). Ainda assim, mesmo que esses clãs não sejam estruturas sociopolíticas de um longo passado, ou mesmo se clã não for a terminologia mais apropriada para definir essas articulações políticas de ampla territorialização, o modelo de Terrenato ainda me parece um excelente ponto de partida para elaborar uma reflexão sobre a institucionalidade política romana.

Ao fugir da centralidade dada ao Estado romano como instituição em si, o modelo de Terrenato nos faz pensar sobre a espacialidade das relações sociais que determinam a formação das instituições políticas. O grande mérito desse modelo, a meu ver, é justamente dar conta do desenvolvimento das comunidades políticas das cidades-Estado centro-itálicas, tendo uma escala de análise para além de cada comunidade em si. O desenvolvimento das instituições políticas deixa de ser pensado como uma dinâmica completamente endógena de uma comunidade em isolamento e inclui o problema da interação regional - e mesmo mais ampla - entre classes dominantes locais e supralocais.

A base empírica do modelo de Terrenato é uma série de histórias que atestam a circulação e a mobilidade horizontal de membros de famílias aristocráticas ou mesmo de famílias aristocráticas inteiras. Essas são histórias há muito notadas, e apontar para essa mobilidade não é exatamente uma novidade. O que ele propõe de inovador é deixar de identificar essa mobilidade como meras migrações entre comunidades. O que permite a mobilidade de membros da classe dominante entre diferentes comunidades sem que percam sua posição social são as articulações entre esses grupos da classe dominante inseridos em comunidades diferentes.

As fronteiras políticas desse período são facilmente perpassadas por interações sociais horizontais entre as elites. E é preciso estar atento para o fato de que o próprio 
processo de formação dessas comunidades, que acabará por levar ao fechamento dessas fronteiras em algum nível (GUARINELLO, 2013, p. 78-79), está determinado por essa característica de sua classe dominante. Assim, seria impossível entender a formação das instituições políticas dessas cidades-Estado em uma escala que se reduzisse a uma comunidade isoladamente. Isto é, as instituições cívicas singulares que se formam não são explicáveis apenas pela realidade social interna ao espaço sobre o qual elas irão se estabelecer.

Dois pontos me parecem poder ser desenvolvidos tomando essa ideia de Terrenato como ponto de partida.

Em primeiro lugar, a base camponesa desse mundo, ignorada nesse modelo, precisa ser reinserida nele. Apesar de a tese clássica de revolução hoplítica ter sido questionada já há algum tempo, a relação entre o campesinato e a atividade militar continua sendo incontornável para entender o desenvolvimento da cidade-Estado mediterrânica antiga (SNODGRASS, 1993, p. 61; RAAFLAUB, 2003, p. 28-30). É impossível entender a emergência do conceito de cidadania e a importância política que instituições populares, como as assembleias, vão ter nesse mundo sem garantir aos camponeses algum protagonismo histórico.

A base camponesa da comunidade é a chave para entender por que os grupos da classe dominante buscam justamente as comunidades das cidades-Estado para se articular. Repare bem: no modelo de Terrenato, o centro de articulação poderia muito bem ser um local de culto, um templo ou um palácio principesco. Talvez seja possível, inclusive, criar modelos nessa linha para explicar a interação de grupos da classe dominante no Mediterrâneo da Idade do Bronze, quando locais como esses parecem ter desempenhado papel central na organização política e social.

Por que, então, as cidades-Estado predominam como centro de articulação no Mediterrâneo da Idade do Ferro? Porque aqueles grupos da classe dominante que se articulam de maneira bem-sucedida nesses locais conseguem enormes vantagens políticas, sociais e militares sobre os outros grupos.

Eles passam a ter à disposição um poder considerável, substanciado na comunidade camponesa - poder militar, em primeiro lugar, mas não apenas. Para além de seus familiares, clientes e dependentes diretos, esses grupos agora têm o poder de mobilizar a comunidade de seus concidadãos - que incluem os dependentes de outros grupos da classe dominante com quem se articulam, mas também camponeses independentes ligados a eles pela construção dessa comunidade cívica.

Assim, a questão étnica ganha um papel fundamental na arena política, fenômeno que alguns especialistas chegam a apontar como um desenvolvimento fundamental das formas estatais mediterrânicas e próximo-orientais entre o fim da Idade do Bronze e o início da Idade do Ferro (LIVERANI, 2016, p. 536-540). Esse ponto é importante para nos precaver de incorrer no erro de pensar toda a dinâmica política e militar do período como um teatro de sombras das classes dominantes. Lealdades e identidades, institucionalidades e pertencimentos daqueles que lutam as guerras do período desempenham papel crucial.

Em segundo lugar, a reflexão de Terrenato serve não só para o momento formativo das instituições da cidade-Estado, mas para toda a sua história de desenvolvimento e constante transformação. Assim, toda a rica narrativa de transformações institucionais romanas - como a formação da monarquia tarquínia, o surgimento da República, o fechamento do patriciado, a emancipação da plebe e assim por diante - precisa ser explicada para além da história interna de Roma. Ou, melhor dizendo, a história interna 
de Roma precisa ser dissolvida em uma complexa história que necessariamente demanda variação de escalas geográficas.

Como isso pode nos ajudar a entender o estudo de caso deste artigo? Ou como este estudo de caso nos ajuda a materializar essas reflexões gerais? Em meados do século IV a.C., aparentemente temos uma séria pressão por rearticulação das instituições políticas centro-itálicas. De alguma forma sobre a qual não temos informações, grupos da classe dominante centro-itálica que não tinham acesso à fechada elite política patrícia utilizaram o movimento plebeu como caminho para produzir um meio de rearticulação da classe dominante regional. Os Pláucios seriam um exemplo extremamente bem-sucedido disso. Não só conseguem entrar com sucesso no centro de poder dessa institucionalidade, como têm êxito em mobilizá-la com frequência para impor sua agenda sobre os territórios que lhes são especialmente sensíveis.

Isso não significa que esses grupos da elite tenham apenas instrumentalizado o movimento plebeu. Se a vitória plebeia foi uma rearticulação dentro da classe dominante, também foi uma rearticulação dessa classe dominante com a base camponesa romana. A menção em Tito Lívio de que Caio Pláucio Venão esteve envolvido nas demandas por corte de taxas de juros, uma pauta tradicional plebeia, pode ser uma notícia histórica de um exemplo desse tipo de rearticulação (TERRENATO, 2014, p. 49).

A emancipação da plebe, todavia, faz parte de um contexto maior de conflitos e projetos de rearticulação institucional ao longo do século IV a.C. Interpreto que muitas guerras dessa época tradicionalmente entendidas como lutas de determinadas cidades contra a dominação romana eram, na verdade, batalhas complexas em torno das rearticulações dentro da classe dominante centro-itálica e desta com as bases camponesas das comunidades da região. Existem diversos projetos de rearticulação política em jogo, e se os Pláucios são um exemplo de projeto bem-sucedido, devemos buscar os exemplos de projetos malsucedidos. A Guerra Latina me parece ser um deles.

$\mathrm{Na}$ narrativa de Tito Lívio, campânios, sedicinos e latinos se articulam para combater a ameaça vinda dos Samnitas, mas logo essa aliança aparece se envolvendo em conflitos com Roma. É interessante que esses conflitos emergem, no texto de Lívio, logo após sua narrativa sobre a incorporação da importante cidade de Cápua ao sistema político romano (Tito Lívio, Desde a fundação da Cidade, 7.28-30). É impossível saber em que nível de detalhe é prudente confiar nas informações de Lívio, mas chama a atenção o fato de essas duas aparecerem de maneira subsequente na narrativa liviana.

Os tentáculos do poder da classe dominante, que se articulava por via da institucionalidade romana, atingem uma nova escala geográfica nesse momento. A Campânia é arrastada para o palco de disputa. Aparentemente, a articulação entre grupos das classes dominantes organizadas em duas das mais proeminentes cidades da Itália central tirrênica, Roma e Cápua, levou diversos outros grupos organizados em outras cidades a buscarem uma articulação para fazer frente a esse poderio enorme que se constituía. Isso desencadeou o que passou para a história como a "rebelião dos latinos".

Os grupos latinos que se organizam de maneira antagônica à Roma entre 341 e 338 a.C. poderiam estar buscando uma forma distinta para a rearticulação do que aquela que vinha se constituindo com a emancipação da plebe. $O$ discurso recriado por Tito Lívio do líder latino Lúcio Ânio no Senado romano, por exemplo, remete à exigência de formação de uma entidade política latino-romana, com um cônsul latino e outro romano, assim como metade do Senado sendo formada por latinos (Tito Lívio, Desde a fundação da Cidade, 8.3-5). 
Um modelo de consulado compartilhado entre um latino e um romano - em vez de um plebeu e um patrício, como recentemente havia sido estipulado - poderia ser interpretado como um caminho de rearticulação alternativo àquele que vinha sendo traçado até então, exigido por grupos que estavam menos inseridos no núcleo de poder romano - isto é, fora da nobilitas patrício-plebeia que vinha se formando. Contudo, é muito provável que a recriação de Lívio das reivindicações latinas nessa revolta esteja sob influência do que ele sabia sobre as demandas dos italianos na Guerra Social do início do século I a.C. (FORSYTHE, 2006, p. 289) e, portanto, é imprudente tirar muitas conclusões com base nos detalhes de sua narrativa.

A informação de que houve uma ampla reforma nas relações de aliança entre Roma e essas cidades, entretanto, é bastante sólida e pode ser reinterpretada no modelo que estou propondo, ou seja, que o novo sistema que emerge em 338 a.C. é resultado de um processo de articulação, disputa e conflito tanto entre os diversos grupos da classe dominante regional quanto destes com as diversas comunidades camponesas da região, frente à consolidação e à expansão do poder do sistema organizado em torno da República romana.

Essas disputas geram transformações em toda a cadeia institucional que articula os sistemas de poder da região. No que é normalmente entendido como história interna romana, há reformas das instituições políticas - inclusão dos plebeus nas altas magistraturas, oligarquização do funcionamento das magistraturas e novo papel do Senado. Naquilo que é chamado de história externa de Roma, há a criação de uma nova rede hierárquica de status de relação entre as cidades-Estado da região, que consolidava as instituições da res publica romana como o centro de poder ao mesmo tempo que reformava a relação dessas instituições com as das outras cidades-Estado.

As diversas institucionalidades que vão sendo construídas para incorporar diferentes comunidades, que com o tempo vão sendo enquadradas em tipos mais específicos - município, município sem sufrágio, colônia latina, cidade aliada -, são resultado dessa rearticulação.

Essa reação latina à incorporação de Cápua ao sistema romano, todavia, não inaugura a pressão por rearticulação. $\mathrm{Na}$ verdade, é o sucesso político-militar da articulação em torno da res publica controlada pelos patrícios nas décadas anteriores que parece ter causado uma reação em cadeia por toda a Itália central. A segunda metade do século $\mathrm{V}$ e o início do século IV a.C., além de marcados pelo "fechamento do patriciado", também assistem à retomada das conquistas militares romanas depois de algumas décadas de "crise" (COLONNA, 1990).

Existem muitas dúvidas sobre a cronologia desse conflito apresentada por Tito Lívio, mas é possível ter alguma convicção de que, em 427 a.C., Fidenas foi conquistada por Roma. A seguir, uma série de conquistas de cidades ao sul de Roma, tomadas principalmente de volscos e équos, é citada em Tito Lívio - a começar por Labico, em 418 a.C., passando por Bola, em 415 a.C., e Terrancina/Anxur, em 406 a.C. (Tito Lívio, Desde a fundação da Cidade, 4.45-47, 4.49.2-5, 4.59).

O caso mais importante e paradigmático desse novo momento é a conquista de Veios. Os relatos de destruição são bastante impressionantes, e acredito que tenham relação com o fato de essa conquista ter sido mais que uma batalha dentro de um quadro conflituoso de rearticulações da classe dominante regional. Tratou-se de uma conquista territorial mais drástica (Tito Lívio, Desde a fundação da Cidade, 5.1-24). Isso poderia explicar por que os levantamentos de superfície na região identificam uma importante reorganização do assentamento no território veiense 
nesse período. O controle sobre a propriedade da terra nessa região passa por uma grande transformação após a conquista romana (PATTERSON et al., 2004). O controle direto sobre esse território tão vasto e rico coloca o sistema político controlado pelo patriciado em um novo patamar. Essas conquistas estão associadas também ao que parece ser uma nova política de fundação de colônias.

O núcleo de poder constituído pelos patrícios parece bem-sucedido em uma expansão centrífuga, derrotando adversários e incorporando territórios ao seu sistema de poder. Esse poderio expansivo romano deve ter pressionado os diferentes grupos sociais da região a buscarem novas articulações. Em alguns casos, isso parece ter sido feito com o próprio grupo patrício e seus aliados, colocando-se sob as asas do sistema patrício ou articulando alianças com ele.

Os textos antigos contam que os cidadãos de Túsculo se submeteram voluntariamente a Roma em 381 a.C. (Tito Lívio, Desde a fundação da Cidade, 6.2526), tornando-se o primeiro município romano (Cícero, A favor de Plâncio, 19), e que os cidadãos de Cere passaram a ter status especial em Roma depois de sua benevolência com os romanos durante o saque gaulês de 410 (Tito Lívio, Desde a fundação da Cidade, 5.40 e 5.50; Valério Máximo, Feitos e ditos memoráveis, 1.1.10; Plutarco, Camilo, 21; Aulo Gélio, Noites Áticas, 16.13.7; Estrabão, Geografia, 5.2.3; Corpus Inscriptionum Latinarum VI.1272). Ambas as histórias podem ser formas centrípetas de expansão do sistema de poder patrício.

Outro caminho teria sido justamente a tentativa de subverter por dentro o sistema patrício, abrindo-o aos plebeus e constituindo uma nova elite política, que foi bem-sucedido ao longo do século IV a.C. e do qual os Pláucios são nosso exemplo. Por fim, um terceiro caminho foi a articulação antagônica aos grupos que controlavam as instituições da res publica, fazendo eclodir revoltas que, se por um lado foram derrotadas militarmente, por outro forçaram a rearticulação do sistema de alianças romano.

O reajuste de 338 a.C. também não dá fima esta pressão. Aqueles que enfrentaram as legiões romanas lideradas por Pláucios contra Priverno nos dão um excelente indício disso. O personagem que Tito Lívio identifica como líder da rebelião de Priverno e Fundos em 330 a.C., Mário Vitrúvio Vaco, era um rico nativo de Fundos que tinha uma luxuosa mansão no Palatino (Tito Lívio, Desde a fundação da Cidade, 8.19.4). Ou seja, Vitrúvio Vaco não era o líder patriota anti-Roma de uma revolta nacionalista buscando independência, e sim parte dessa classe dominante regional, construindo estratégias para aumentar seu poder por meio de redes e instituições políticas disponíveis; era, provavelmente, rival dos Pláucios nas vizinhanças de Priverno.

Talvez fosse também, mas aqui estou especulando, o fiador de uma tentativa de nova articulação com algumas bases camponesas na região do Lácio, que envolvia o enfrentamento com os grupos articulados pela institucionalidade romana, o que talvez explique os ataques às colônias romanas na região. O fato de Lívio contar que senadores Fundanos suplicaram aos romanos dizendo que nada tinham a ver com Vitrúvio (Tito Lívio, Desde a fundação da Cidade, 8.19.10-11) pode ser, por outro lado, a ponta de uma informação histórica sobre a existência de grupos anti-Vaco (e talvez pró-Pláucios) na cidade. Mais do que uma guerra entre nações, estamos diante, pois, de conflitos entre grupos da classe dominante que se articulam de maneiras dinâmicas e nos espaços de poder disponíveis com as bases camponesas das regiões em que atuam (TERRENATO, 2014, p. 51-52). 


\section{CONCLUSÕES E PERSPECTIVAS}

Roma não é, portanto, um agente histórico em si, como normalmente é tratada. É uma plataforma de poder utilizada e disputada por pessoas que vivem tanto dentro quanto fora daquilo que, sob algum critério, poderíamos definir como Roma - até porque teríamos enorme dificuldade em chegar a algum critério que parecesse razoável. Isso só pode ser percebido se deixarmos de lado a rígida dicotomia entre história interna e história externa. A partir disso, escalas geográficas diferentes precisam ser usadas para identificar agentes e processos que nos ajudam a entender os fenômenos históricos que observamos.

Neste artigo, explorei quanto agentes e processos históricos da Itália central, sobretudo em sua porção tirrênica, precisam ser compreendidos para dar conta da dinâmica histórica daquilo que a princípio poderia ser entendido como história interna de Roma. Isso significa conectar essas histórias, ou, talvez mais do que isso, solvê-las uma na outra. A história da guerra e da paz entre Roma e as cidades centro-italianas é, na verdade, uma narrativa de conflito e alianças entre diversos grupos de poder que criam, dissolvem e transformam institucionalidades e identidades políticas. É por isso que a expansão romana e a emancipação da plebe precisam ser pensadas como facetas de uma mesma história.

O escopo geopolítico que este artigo abordou, entretanto, não é um limite necessário para esse processo de reenquadramento geográfico da história da República Romana. Pelo contrário, essa é ainda uma escala reduzida. A história externa que precisa ser trazida para este tipo de reflexão pode ser mais ampla. Como dito, a história do conflito social romano parece reproduzir um padrão bem comum de conflitos ao redor do Mediterrâneo na mesma época. Da mesma forma, a construção de um sistema político de grande escopo geográfico e militar em torno de Roma, na segunda metade do século IV a.C., também é comparável com processos ocorridos em outras partes do Mediterrâneo, como o sistema político cartaginês e as monarquias helenísticas. Superar enquadramentos "internalistas" e identificar como essas diferentes histórias estão conectadas pode ser o próximo passo na superação dos limites impostos pelo internalismo metodológico em nossos estudos.

\section{REFERÊNCIAS}

AMPOLO, Carmine. Demarato, osservazioni sulla mobilità sociale arcaica. Dialogues d'histoire ancienne, Besançon, n. 9-10, p. 333-345, 1977.

AULO GÉLIO. Noites Áticas. Londrina: Eduel, 2010.

BLOCH, Marc. Apologia da história. Rio de Janeiro: Zahar, 2002.

BRADLEY, Guy Jolyon; ISAYEV, Elena; RIVA, Corinna (org.). Ancient Italy: Regions without Boundaries. Exeter: University of Exeter Press, 2007.

BROUGHTON, T. Robert S. The Magistrates of the Roman Republic: 509 B.C.-100 B.C. v. 1. Atlanta: Scholars Press, 1951. 
BRUNT, P. A. Social Conflicts in the Roman Republic. London: Hogarth, 1986.

CASSOLA, F. Lo scontro fra patrizi e plebei e la formazione della "nobilitas". In: MOMIGLIANO, Arnaldo; SCHIAVONE, Aldo (Ed.). Storia di Roma I: Roma in Italia. Torino: G. Einaudi, 1988. p. 145-175.

CHERNILO, Daniel. The Critique of Methodological Nationalism: Theory and History. Thesis Eleven, Clayton, v. 106, n. 1, p. 98-117, 2011.

CHERNILO, Daniel. Methodological Nationalism. In: CHERNILO, Daniel. The WileyBlackwell Encyclopedia of Social Theory. New York: Blackwell, 2017. p. 1-3.

CíCERO. A favor de Plâncio. In: N.H. Watts (ed.). Pro Archia. Post Reditum in Senatu. Post Reditum ad Quirites. De Domo Sua. De Haruspicum Responsis. Pro Plancio. Cambridge, Mass.: Harvard University Press, 1923.

COLONNA, Giovanni (org.). Crise et transformation des sociétés archaïques de I'Italie antique au Ve siècle J.-C. Actes de la table ronde de Rome (19-21 novembre 1987). Roma: École Française de Rome, 1990.

CONRAD, Sebastian. What Is Global History? Princeton: Princeton University Press, 2016.

CORNELL, Tim. The Beginnings of Rome: Italy and Rome from the Bronze Age to the Punic Wars (c.1000-264 BC). London: Routledge, 1995.

Corpus Inscriptionum Latinarum. Berlin-Brandenburg Academy of Sciences and Humanities (ed.). 1853-.

DE SANCTIS, Gaetano. Storia dei Romani, vols. I-II: La conquista del primato in Italia. Torino: Fratelli Bocca, 1907.

ESTRABÃO. Geografia. Coimbra: Imprensa da Universidade de Coimbra, 2016.

FARNEY, Gary D.; BRADLEY, Guy. The Peoples of Ancient Italy. Berlin: Walter de Gruyter GmbH \& Co KG, 2017.

FESTO. Sobre o significado das palavras. In: De Verborum Significatione. Edited by Wallace Lindsay. Leipzig: Teubner, 1913.

FORSYTHE, Gary. A Critical History of Early Rome: From Prehistory to the First Punic War. Berkeley: University of California Press, 2006.

FUKS, Alexander. Social Conflict in Ancient Greece. Leiden: Brill, 1984.

GUARINELLO, Norberto Luiz. História Antiga. São Paulo: Contexto, 2013.

HARRIS, William V. Rome in Etruria and Umbria. Oxford: Clarendon Press, 1971. 
HOBSBAWM, Eric J.; RANGER, Terence (org.). Invenção das tradições. Rio de Janeiro: Paz e Terra, 1997.

HUMBERT, Michel. "Municipium" et "civitas sine suffragio": l'organisation de la conquête jusqu'à la guerre sociale. Rome: École française de Rome, 1978.

LIVERANI, Mario. Antigo Oriente. São Paulo: EDUSP, 2016.

MATIN, Kamran. Redeeming the Universal: Postcolonialism and the Inner Life of Eurocentrism. European Journal of International Relations, London, v. 19, n. 2, p. 353-377, 2013.

MOMIGLIANO, Arnaldo. The Rise of the Plebs in the Archaic Age of Rome. In: RAAFLAUB, Kurt A. (org.) Social Struggles in Archaic Rome: New Perspectives on the Conflict of the Orders. Malden: Blackwell, 2005. p. 168-184.

MOURITSEN, Henrik. The Civitas Sine Suffragio: Ancient Concepts and Modern Ideology. Historia: zeitschrift für alte geschichte: revue d'histoire ancienne, Stuttgart, v. 56, n. 2, p. 141-158, 2007.

PATTERSON, Helen et al. The Re-evaluation of the South Etruria Survey: The First Results from Veii. In: PATTERSON, Helen (org.). Bridging the Tiber: Approaches to Regional Archaeology in the Middle Tiber Valley. (Archaeological Monographs of the British School at Rome, n. 13.) London: British School at Rome, 2004. p. 11-28.

PLUTARCO. Camilo. In: PLUTARCO. Vidas Paralelas. São Paulo: Paumape, 1991.

RAAFLAUB, Kurt A. Politics and Society in Fifth-Century Rome. In: LEVI, M.A. (org.). Bilancio critico su Roma arcaica fra monarchia e repubblica. In memoria di F. Castagnoli. Atti del Convegno (Roma, 3-4 giugno 1991). Roma: Accademia Nazionale dei Lincei, 1993.

RAAFLAUB, Kurt A. Soldiers, Citizens, and the Evolution of the Early Greek Polis. In: MITCHELL, Lynette; RHODES, P. J. The Development of the Polis in Archaic Greece. London: Routledge, 2003. p. 26-31.

RAAFLAUB, Kurt A. From Protection and Defense to Offense and Participation: Stages in the Conflict of the Orders. In: RAAFLAUB, Kurt A. (ed.). Social Struggles in Archaic Rome: New Perspectives on the Conflict of the Orders. Malden: Blackwell, 2005a. p. 185-222.

RAAFLAUB, Kurt A. The Conflict of the Orders in Archaic Rome: A Comprehensive and Comparative Approach. In: RAAFLAUB, Kurt A. (ed.). Social Struggles in Archaic Rome: New Perspectives on the Conflict of the Orders. Malden: Blackwell, 2005b. p. $1-46$. 
ROTH, Roman Ernst. Styling Romanisation: Pottery and Society in Central Italy. (Cambridge Classical Studies.) Cambridge: Cambridge University Press, 2007.

ROTH, Roman Ernst; KELLER, Johannes. Roman by Integration: Dimensions of Group Identity in Material Culture and Text. Portsmouth: Journal of Roman Archaeology, LLC, 2007.

RUOFF-VÄÄNÄNEN, Eeva. The Civitas Romana-Areas in Etruria before the Year 90 B.C. In: BRUUN, Patrick. Studies in the Romanization of Etruria. (Acta Instituti Romani Finlandiae, 5) Roma: G. Bardi, 1975. p.33-68.

SCOPACASA, Rafael. Ancient Samnium: Settlement, Culture, and Identity between History and Archaeology. Oxford: Oxford University Press, 2015.

SMITH, Christopher. The Roman Clan: The Gens from Ancient Ideology to Modern Anthropology. Cambridge: Cambridge University Press, 2006.

SNODGRASS, Anthony M. The 'Hoplite Reform' Revisited. Dialogues d'histoire ancienne, Besançon, v. 19, n. 1, p. 47-61, 1993.

STE. CROIX, Geoffrey Ernest Maurice De. The Class Struggle in the Ancient Greek World: From the Archaic Age to the Arab Conquests. Ithaca: Cornell University Press, 1989.

TERRENATO, Nicola. The Versatile Clans: Archaic Rome and the Nature of Early City-States in Central Italy. In: TERRENATO; Nicola; HAGGIS, Donald C. (ed.). State Formation in Italy and Greece: Questioning the Neoevolutionist Paradigm. Oxford: Oxbow, 2011. p. 231-244.

TERRENATO, Nicola. Private Vis, Public Virtus. Family agendas during the early Roman expansion. In: PELGROM, Jeremia; STEK, Tesse Dieder (ed.). Roman Republican Colonization: New Perspectives from Archaeology and Ancient History. (Journal of Roman Archaeology Supplementary Series.) Portsmouth, R.I: Journal of Roman Archaeology, 2014. p. 45-59.

TITO LÍVIO. Desde a fundação da Cidade. 6 vols. São Paulo: Paumape, 1990.

TORELLI, Mario. Tota Italia: Essays in the Cultural Formation of Roman Italy. Oxford: Clarendon Press, 1999.

VALÉRIO MÁXIMO. Feitos e ditos memoráveis. In: BAILEY, D. R. Shackleton (ed.). Memorable Doings and Sayings. 2 vols. Cambridge, Mass.: Harvard University Press, 2000. 


\title{
NOTAS
}

\author{
AUTORIA \\ José Ernesto Moura Knust: Doutor. Professor do ensino básico, técnico e tecnológico, Instituto \\ Federal Fluminense, Macaé, RJ, Brasil.
}

\section{ENDEREÇO PARA CORRESPONDÊNCIA}

Rodovia Almirante Peixoto, Km 164, 27973-030, Imboassica, Macaé, RJ, Brasil.

\section{ORIGEM DO ARTIGO}

Artigo desenvolvido a partir de reflexões produzidas na minha tese de doutorado - Longe dos muros: uma história econômica e social do assentamento rural na Itália central tirrênica no contexto da conquista romana (séculos $V$ a III a.C.) -, apresentada ao Programa de Pós-graduação em História da Universidade Federal Fluminense em 2016.

\section{AGRADECIMENTOS}

Agradeço a todos que conversaram comigo sobre o tema deste artigo e/ou leram versões de partes deste texto e contribuíram com sugestões, como Sônia Rebel, minha orientadora de Doutorado, Paulo Pachá, Fábio Frizzo, Mário Jorge da Motta Bastos, Eduardo Daflon e Thiago Magella.

\section{FINANCIAMENTO}

Este artigo foi financiado com bolsa do Conselho Nacional de Desenvolvimento Científico e Tecnológico (CNPq), da Coordenação de Aperfeiçoamento de Pessoal de Nível Superior (CAPES) e da Fundação Carlos Chagas Filho de Amparo à Pesquisa do Estado do Rio de Janeiro (FAPERJ).

\section{APROVAÇÃO DE COMITÊ DE ÉTICA EM PESQUISA \\ Não se aplica.}

\section{CONFLITO DE INTERESSES}

Não houve conflito de interesse.

\section{LICENÇA DE USO}

Este artigo está licenciado sob a Licença Creative Commons CC-BY. Com essa licença você pode compartilhar, adaptar, criar para qualquer fim, desde que atribua a autoria da obra.

\section{PUBLISHER}

Universidade Federal de Santa Catarina. Programa de Pós-Graduação em História. Portal de Periódicos UFSC. As ideias expressadas neste artigo são de responsabilidade de seus autores, não representando, necessariamente, a opinião dos editores ou da universidade.

\section{EDITORES}

Alex Degan

Beatriz Mamigonian

Fábio Augusto Morales

Flávia Florentino Varella (Editora-chefe)

Tiago Kramer de Oliveira

Waldomiro Lourenço da Silva Júnior

\section{HISTÓRICO}

Recebido em: 1 de março de 2019

Aprovado em: 7 de abril de 2019

Como citar: KNUST, José Ernesto Moura. Os Pláucios, a emancipação da plebe e a expansão romana: conectando as histórias interna e externa da República Romana. Esboços, Florianópolis, v. 26, n. 42, p. 234-254, maio/ago. 2019 